\title{
R-ACVBP Regimen
}

National Cancer Institute

\section{Source}

National Cancer Institute. R-ACVBP Regimen. NCI Thesaurus. Code C140658.

A regimen consisting of doxorubicin, cyclophosphamide, vindesine, bleomycin,

prednisone and rituximab that can be used in the treatment of non-Hodgkin lymphoma (NHL). 